\title{
Measurement of Dielectric Properties in Microwave Frequencies
}

\author{
R.K Das* \\ Dept. of Physics, Charuchandra College, University of Calcutta, Kolkata, India \\ "Corresponding Author: rkdas_171171@rediffmail.com
}

Available online at: www.isroset.org

Received 28/Dec/2017, Revised 10/Jan/2018, Accepted 29/Jan/2018, Online 28/Feb/2018

\begin{abstract}
In this review paper dielectric constant of different types of soils, agricultural food materials and different types of stones have been discussed here. And different types of methods for determination of dielectric constant have also been discussed here. The dielectric constant of soil depends upon the moisture content of soil. Previous results shows bound water in soil water affects the dielectric properties of soil and relationship between dielectric properties with gravimetric water content is nonlinear. The factor affecting the dielectric properties of agricultural food materials are frequency, moisture content, temperature and density. Since moisture content is often the most important characteristic of agricultural products. The dielectric constant and loss factor of all food materials decreased with increasing frequency but increased with increasing temperature. In the case of marbles also the presence of moisture and impurities are the main factors affecting the dielectric properties. Agriya marble has highest dielectric constant and sandstone and limestone has the least. The increase in the percentage of impurity in the chemical composition of marbles affects dielectric property at low frequency region.
\end{abstract}

Keywords-Dielectric, Marble, Agri-foods, Moisture content, Temperature, Frequency

\section{INTRODUCTION}

Dielectrics are the materials which are poor conductor of electricity in comparison to metals which are very good conductor of electricity. In past few decades the study of dielectric properties of different soil samples, Agricultural products, minerals ( different types of stones ) are the emerging field of study. There are many experiments which denote the study of dielectric properties of different types of soils in which microwave measurement technique plays important role. The dielectric constant of soil depends on the moisture content of soil [1]. Different methods have been used here to study dielectric constants at microwave frequency [2,3]. For example dielectric constant of red soil in the frequency range of $\mathrm{GHz}$ has been calculated [4]. Also dielectric constant of brown and black soils have been measured here [5]. The soil sample with diesel oil content in it in the frequency range of $\mathrm{MHz}$ have been measured [6]. Dielectric constants of soils collected from Bidar region of Karnataka state are studied here [7]. In this paper the real and imaginary parts of dielectric constant have been studied for soils with different moisture or water content [8]. This results shows bound water in soil water affects the dielectric properties of soil and relationship between dielectric properties with gravimetric water content is nonlinear.

There are several technique to measure the dielectric properties of agri-food materials. The dielectric properties of these agricultural food materials in the microwave region can be measured by several methods have been discussed in this paper. The factor affecting the dielectric properties of agricultural food materials are frequency, moisture content, temperature and density. Since moisture content is often the most important characteristic of agricultural products. In addition to moisture content measurement the dielectric properties measurement is also useful in diagnostic tests and for processing of materials (agrifoods, pharmaceuticals, biomedical, forestry, textile, metallurgy etc). Methods of measuring dielectric properties of granular and powdered materials at microwave frequencies and factor affecting the dielectric properties of materials such as frequency, moisture content, temperature and bulky density were reviewed earlier [9].

Dielectric properties of various decorative stones at microwave frequencies have been measured [10]. AGRIYA marble has highest dielectric constant due to compact nature and less amount of impurities with moist samples the dielectric constant increases due to absorption of water molecules. The sand stone and lime stone shows least dielectric constant. Dielectric properties of solid Coal and Limestone are measured at $11.7 \mathrm{GHz}$ and $20^{\circ} \mathrm{C}$ [11].

In this review paper dielectric constant of different types of soils, agricultural food materials, different types of stones have been discussed here. And different types of methods for determination of dielectric constant have been discussed here.

This paper has been written into four distinct sectionsIntroduction, Experimental procedure, Results and discussion and conclusion. Introduction section gives brief review of literature related to present work done. Experimental 
procedure gives the different methods used for determining dielectric constant. Results and discussion section gives the results drawn in this paper. Conclusion part gives the major conclusion drawn here.

\section{EXPERMENTAL PROCEDURE}

For measurement of dielectric constant at low frequencies a coaxial sample holder having large surface area was used with a General Radio 1608- a precision impedence bridge and an external audio-frequency oscillator is used. For measurement in the frequency range 1-50 $\mathrm{MHz}$ a coaxial sample holder with the Boonton 160-AQ meter was used by using the principle of series resonance technique. In the frequency range 50 to $250 \mathrm{MHz}$ a coaxial sample holder was constructed and used with a Boonton 250-A RX Meter to measure the dielectrics properties of Agri-food products. For the measurement in the frequency range 200 to $500 \mathrm{MHz}$ a coaxial sample holder was used with General Radio 1602-B U-H-F Admittance Meter and auxillary oscillators, power supply, detector and $50 \mathrm{ohm}$ GR-874 line components were used [12]. At microwave frequencies two different techniques are found suitable. A waveguide measurement technique in which the material sample is placed inside the waveguide in contact with short circuit connection. This technique is suitable for granular and powered materials. For larger samples free space transmission measurement technique with a network analyzer is used.

For the measurement of decorative stones at $\mathrm{X}$ band microwave frequencies, rectangular wave guide operating at TE10 mode is used.

\section{RESULTS AND DISCUSSIONS}

The dielectric constant of soil with low moisture is low and as the moisture content of the soil increases the dielectric constant of the soil also increases. The dielectric constant of sandy soil is more than clay soil. In marble stone also moisture content affects the dielectric constant. With moist sample the dielectric constant increases due to increase in hydration ions in it. The dielectric constant is higher if the amount of impurities associated with it is less. Agriya marble has highest dielectric constant where as sandstones and limestones have least dielectric constant. Dielectric properties of pulverised Coal Sample and limestone from different sources were measured at $20^{\circ} \mathrm{C}$ over a frequency range about $11.7 \mathrm{GHz}$. Dielectric constants decreased regularly with increased frequency in the case of these minerals.

\section{ConclusionS}

Water content in the soil significantly affects the dielectric properties of different soils. There are several methods to measure the dielectric constants of soils, Agri-food materials and different minerals discussed above. The dielectric constant and loss factor of all food materials decreased with increasing frequency but increased with increasing temperature. Previous results shows bound water in soil water affects the dielectric properties of soil and relationship between dielectric properties with gravimetric water content is nonlinear. The factor affecting the dielectric properties of agricultural food materials are frequency, moisture content, temperature and density. The dielectric constant and loss factor of all food materials decreased with increasing frequency but increased with increasing temperature. In the case of marbles also the presence of moisture and impurities are the main factors affecting the dielectric properties. Agriya marble has highest dielectric constant and sandstone and limestone has the least. The increase in the percentage of impurity in the chemical composition of marbles affects dielectric property at low frequency region.

\section{ACKNOWLEDGMENT}

I am thankful to Principal and Department of Physics, Charuchandra College, University of Calcutta for giving me support.

\section{REFERENCES}

[1] P. V. Narasimha Rao, C. Suresh Raju, K.S. Rao, “ Transsactions on Geoscience and Remote Sensing", IEEE, vol.28, pp.148,1990.

[2] O.P.N. Calla, Vivek Ranjan, Chetan Bohra, G.L. Naik, "Estimation of Dielectric constant of soil from the given texture at microwave frequency", Indian Journal of Radio and Space Physics, vol.33, pp.196-200, 2004.

[3] O.P.N. Calla, A. Baruah, B. Das, K.P. Misra, M. Kalita, S.S. Haque, "Variability of dielectric constant of dry soil with its Physical constituents at microwave frequencies and validation of the CVCG model', Indian Journal of Radio and Space Physics, vol.33, pp.125129, 2004.

[4] Vijaya Puri, S. Darshanne, S. Shaikh, “ Moisture dependent $K U$ band microwave characteristics of red soil", Indian Journal of Radio and Space Physics, vol.33, pp.399-404, 2004.

[5] Vijaya Puri, S. Darshanne, S. Shaikh, "KU band microwave transmission and reflection of moistureladen brown and black soil", Indian Journal of Physics, vol.79, pp.1419-1422, 2004.

[6] S. Darayan, C. Liu, L.C. Shen, D. Shattuck, “ Measurement of Electrical properties of contaminated soil”, Geophysical Prospecting, vol.46, pp.477-488, 1998.

[7] H.C. Chaudhuri, V.J. Shinde, "Dielectric properties of Black and Red soils at microwave frequency", Indian Journal of Radio \& Space Physics, vol.39, pp.103106,2010 . 
[8] H.C. Chaudhuri \& V.J. Shinde, "Dielectric properties of soils at $X$ band microwave frequency", Indian Journal of Pure \& Applied Physics, vol.50, pp.6466,2012.

[9] S.O. Nelson, “ Measurement of microwave dielectric properties of particulate materials", Journal of Food Engineering, vol.21, Issue 3, pp.365-384, 1994.

[10] P.C. Bapna, S. Joshi, "Measurement of Dielectric Properties of various Decorative Stones at $X$-band Microwave Frequencies", International Journal of Computer Applications, National Conference on Recent Advances in Wireless Communication and Artificial Intelligence (RAWCAI), pp.9-12,2014

[11] S.O. Nelson, "Determining dielectric of Coal and Limestone by measurements on pulverized samples", Journal of Microwave Power and Electromagnetic Energy, vol.31, Issue 4, pp.215-220,1996.

[12] S.O.Nelson, "Fundamental of Dielectric Properties Measurements and Agricultural Applications," Journal of Microwave Power and Electromagnetic Energy, vol.44, pp.98-113, 2010 